\title{
A Dive into Problems of National Health Management Information Systems (NHMIS) in Nigeria
}

\author{
Oluwatuyi Mayowa Funmilayo, \\ Department of Health Information Management, \\ Ekiti State College of Health Sciences and Technology, Nigeria.
}

\begin{abstract}
NHMIS in Nigeria is a design established to collect, store, process and manage health care data in an effective and efficient manner in such a way that it will enhance health care delivery. NHMIS involves collection, storage and the transfer of a patient's EMedical record, An health institution supporting health care policy decisions. National Health Management Information Systems. (NHMIS) promotes efficacious and valid services within hospital settings. NHMIS was introduced in Nigeria precisely 2006 which encompass all health information system. The achievement of NHMIS becomes a mirage due to challenges and problems faced with by health institutions. Be that as it may, it's imperative to have knowledge about determinants for successful implementation to make sure there is qualitative NHMIS. The successfulness of the implementation process of NHMIS is reliant on factors ranging from Technological, personnel and Institutional factors. Any problem relating to heath institutions if pointed out should avert poor implementation in the long run. Thus, this article will review problems of health institution factors affecting the efficacy of NHMIS while considering plans needed to forestall problems earlier identified. This review reveals various problems of NHMIS. Nigeria's NHMIS recorded development and success as a result of weakened Health care system, limited demand due to misplaced focus and the increase in certain diseases like HIV/AIDs, Malaria and TB. The identified challenges have greatly impacted in the health information system
\end{abstract}

\section{INTRODUCTION}

The 2006 National health policy pointed out and recognizes that the health information system is an important part and major thrust of the health system in Nigeria. This policy described and pinpoint that the state of the health system of the Nigeria population is assessed based on incomplete and scanty information. As such, the policy recommends empowering and strengthening the health information system as a management tool for informed decision making at all level of governance. In the fast growing world, all institutions are managed and developed through technological support and health care prioritization. NHMIS is crucial to ensuring and enjoying a standardized health care system [2 ]
NHMIS is not limited to its ability to have detailed information of patient health record as it will help to make decisive decisions on better ways to improve on health services and data management, The electronic approach in NHMIS is important in ways due to the continual opportunities which overshadow its impediments when properly utilized and harnessed despite the complexity of health institution[6]

In some African countries like Nigeria, hospitals especially public owned ones opt for any options of NHMIS. Nevertheless, they all possess and utilize E-system and manually operated system in NHMIS. [6]

NHMIS collects, stores, process and manage health care data in an effective and efficient manner in such a way that it will enhance health care delivery. NHMIS involves collection, storage and the transfer of a patient's E- Medical record, An Health institution supporting health care policy decisions. National Health Management Information Systems while Health Institutions engage in a more holistically wide approach to offer health care services to people with health challenges through collaborative efforts of health teams at all level of health care services [Primary, Secondary and Tertiary[5]

NHMIS application opens room for a broad spectrum modalities to fashion out a model and means for all sectors in health while taking into account financial factors, personnel, purchase of good and services and technology needed strengthen exchange of communication with parties involved. [25] NHMIS is moved to extend its horizon towards provision of quality health care service to individuals and allow the proper storage of patient's health data and its retrieval system. [16] There is room for improvement while considering manual recording of patient data and E-record of same while creating a security system that protects individual record, block E-theft, Virus protection software and restrict access of unauthorized individuals or groups to health data and information of patients in NHMIS. 


\section{METHODOLOGY}

This study aim at identifying the problems hindering effective NHMIS in Nigeria. Nevertheless, to get hold of necessary data needed in other articles. NHMIS encompasses various names used in its substitution.

\author{
$>$ E-Health Records (EHR) \\ $>$ E-Medical Record (EMR), \\ > Healthcare Management System (HMS), \\ $>$ Hospital Information System (HIS), \\ $>$ Health Information system
}

It will be of great impact to note that in the course of this work, I used the word to represent NHMIS at varied interchange. I made efforts to expand my horizon to updated articles. Therefore, articles that do not reflect data on health care information system [HCIS] or articles which are not up to date were left out and not included in my review. Consequently, to have unlimited access to research works on the problem of NHMIS. The database for indexing includes the use of DL, GS, SD and works from publications from different journals such as Research gate publications. The criteria for inclusiveness are from 2011 to 2019 while publications with in-depth analysis on Health institution factors were also reviewed. More so, Exponential implementation cost, managerial boost, effective and secure facilities, privacy with utmost confidentially were mentioned in the article as major Health institutional factors that impedes valid set up of NHMIS in Nigeria. They are therefore discussed below:

\section{HEALTH INSTITUTIONAL PROBLEM}

NHMIS requires not only the knowledge of the system at all which calls for the urgent need to visualize the Health institution as a whole. A Health institution is a facility established by the government to combat health problems of people living in a community with the aim to promote, enhance and sustain health. Due to this, Health institution no doubt plays unique role to boost NHMIS implementation. In addition, health institution is faced with some problems hence, I focused on finding out the problems affecting Health institution in the implementation of NHMIS. Based on past reviews, Health institutions are faced with Exponential implementation cost, managerial boost, and effective and secure facilities, privacy with utmost confidential attitude. However, the hike in Cost is a problem to be noted when it comes to the appraisal of NHMIS and its implementation. The cost in this context continues to prove to be a constant threat to the development of health institutions due to poor networking and sharing of information through computer soft wares and printed materials. Some issues noted are inclusive of problems such as high price and delayed process to welcome NHMIS development as far as Nigeria is concerned. Due to high demand required in investing into NHMIS, demanding maintenance cost and delayed output contributing to limited result. There is need for review of the Government budget towards NHMIS which is expected to cover all aspect needed to acquaint Health Professionals with the new system. Lack of compliance with the level of operation, poor facility, and network, poor budgeting which are of course major concerns that can impede NHMIS implementation in Nigeria.

\section{AVAILABILITY OF HEALTH FACILITIES}

For NHMIS to succeed there is need to key into the idea of a detailed system that involves the availability of facilities such as printed materials, software's, electronic gadgets, WIFI and non WIFI communication system, constant internet services which is managed by a trained ICT person. Inability to key into the above infrastructural wherewithal will limit the scope and validity of NHMIS. NHMIS needs a more detailed instrument though they can come at a steep price but they are worth it. It is equally important to note that NHMIS needs continual and available internet service that will harness constant effort to have access to health information which is vital to any health information system. However, lack of personnel might prove to be a problem in the utilization of these facilities and limit access to data. Health institution in localities experience a little digressed problems ranging from lack of or poor facility, low budgetary allocation, poor network signal, non -access to training and re-training programs on NHMIS and the security of the facilities provided. Medical professional's ability to maintain confidentiality on data of patients knowing fully well that patients do not want their personal health information revealed most especially when dealing with a case history of severe infections. However, unintentional release of patient data can occur, it is not excusable because there should have been measures put in place to secure their health data to have a more working system with back up of information on Google drive and the use of anti-virus to protect the data from wiping with a secured security program to lock and unlock the system. No doubt, Nigeria needs a legal frame work to juxtapose the efficacy of NHMIS policy implementation in the attempt to brush off the possible problems that can impede standardization of NHMIS in Nigeria.

\section{MAP OUT PLAN FOR COMBATING HEALTH INSTITUTION CHALLENGE}

The Nigeria Government through the FMOH has role to play in ensuring continuum in the evaluation and keep on watch list various works, plans and projects on NHMIS, making available health services that is qualitative, efficient, efficacious, accessible and technological knowhow as this this will boost the need to wade into a more scientific research to improve and increase the life and status of everyone. I am moved to identify problems ranging from Employee factor, poor facility at local level and insecure facility as one of the front runners militating against standardized NHMIS in Nigeria as such health institutions are expected to expedite action by suggesting improved budgetary allocation by the Government at both Federal or State level while it is of essence to note that there is need for intersect oral collaboration to be able to meet up with the demands of NHMIS objectively. Be that 
as it may, the need to improve on the team work is necessitated by the optimal goal achievable in NHMIS in Nigeria

\section{> Health Institution and Technological wherewithal}

For many years NHMIS has relied on technology to grow and as such, it is key to ensure proper set up, utilization, standardization, appraisal and conservation of NHMIS. With this, technology made available is expected to be thoroughly utilized or else it lies to waste and lead to infrastructural decay, of what benefit is a system on ground which is not being used? It will eventually lead to wastage of fund. I suggest the need to harmonize procedures in existence to boost the recent program on NHMIS while not undervaluing the importance of previous processes. However, it should be noted that a workable frame work and protection of processes is paramount to achieve good result when it comes securing information in NHMIS. Agencies need to consider the establishment and embrace of all policies in NHMIS with the right support and funding to avert abandonment and shun of the NHMIS and not deviate from what is stated in the security policy.

\section{CONCLUSION}

Laying this review to rest, health institutions, agencies, stakeholders and Federal and State government has major role to play to ensure an efficacious NHMIS. My review shows that NHMIS is a legal frame work established by the government to improve upon the health services provided for the people living in a community with the aim to promote, enhance and sustain health as such NHMIS is a major player in ensuring a valid NHMIS in Nigeria and to sustain this, there is need adequate funding and political support from agencies, government, health professionals, health institutions, all major stakeholders and the community people who are at the receiving end of a laudable NHMIS while also improving on the budgetary allocation appropriated for NHMIS and sensitization of the public on the efficacy of NHMIS in Nigeria.

\section{LIMITATIONS AND FUTURE RESEARCH}

NHMIS is a virgin area in Health Information management considering that it was introduced in the year 2006 which is less than 14 years in Nigeria, focus have been harnessed towards Health information system \{HIS leaving less in-depth review. Certain articles did not address NHMIS in Nigeria hence may not be a reliable comparative study. I recommend a more detailed research work to evaluate NHMIS in Nigeria and its pitfalls backed up with real life facts and an approved policy set in motion to validate NHMIS in Nigeria in comparison with other African countries to start with before scaling up to some developed countries in Europe and Asia

\section{REFERENCES}

[1]. Ahmadi H., Nilashi M., Almaee A., Soltani M., Zare M., Sangar A.B., Osmani M., Ibrahim O., Gerashi M.K , and Razghandi M., "Multi-level model for the adoption of hospital information system: a case on Malaysia," Journal of Soft Computing and Decision Support Systems, vol. 3, no. 1, pp. 61-74, 201

[2]. Silow-Carroll S., Edwards J.N., and Rodin D., "Using electronic health records to improve quality and efficiency: the experiences of leading hospitals," Issue Brief (Commonw Fund), vol. 17, pp. 1-40, 2012

[3]. Grimson J., Grimson W., and Hasselbring W., "The SI challenge in health care," Communications of the $A C M$, vol. 43, no. 6, pp. 48-55, 2000.

[4]. Kaur D.A., "Computerized Hospital Management Information System-Public And Private Sector," Global Journal of Computer Science Research \& Technology, pp. 1123-1134.

[5]. Bays R.A., and Kaelin L. D., "Electronic medical records for the office," Journal of vascular surgery, vol. 51, no. 5, pp. 1302-1308, 2010.

[6]. Anderson J. G., and Aydin C., Evaluating the organizational impact of health care information systems: Springer Science \& Business Media, 2005.

[7]. Chae Y.M., Yoo K. B., Kim E. S., and Chae H., "The adoption of electronic medical records and decision support systems in Korea," Healthcare informatics research, vol. 17, no. 3, pp. 172-177, 2011.

[8]. Buntin M. B., Burke M. F., Hoaglin M. C., and Blumenthal D., "The benefits of health information technology: a review of the recent literature shows predominantly positive results," Health affairs, vol. 30, no. 3, pp. 464-471, 2011.

[9]. Struik M. H., Koster F., Schuit A. J., Nugteren R., Veldwijk J., and Lambooij M.S., "The preferences of users of electronic medical records in hospitals: quantifying the relative importance of barriers and facilitators of an innovation," Implementation Science, vol. 9, no. 1, pp. 69, 2014.

[10]. Latif A. I., Othman M., Suliman A., and Daher A.M., "Current Status, Challenges and Needs for Pilgrim Health Record Management Sharing Network, the Case of Malaysia," International Archives of Medicine, vol. 9, no. 1, 2016.

[11]. Vest J.R., and Gamm L. D. , "Health information exchange: persistent challenges and new strategies," Journal of the American Medical Informatics Association, vol. 17, no. 3, pp. 288-294, 2010.

[12]. Waters E., Rafter J., Douglas G. P., Bwanali M., Jazayeri D., and Fraser H., "Experience implementing a point-of-care electronic medical record system for primary care in Malawi," Stud Health Technol Inform, vol. 160, no. Pt 1, pp. 96-100, 2010.

[13]. Menachemi N., and Collum T.H., "Benefits and drawbacks of electronic health record systems," Risk Manag Healthc Policy, vol. 4, pp. 47-55, 2011. 
[14]. Lian J.-W., Yen D.C., and Wang Y.-T, "An exploratory study to understand the critical factors affecting the decision to adopt cloud computing in Taiwan hospital," International Journal of Information Management, vol. 34, no. 1, pp. 28-36, 2014.

[15]. Scholl J., Syed-Abdul S., and Ahmed L.A., "A case study of an EMR system at a large h ospital in India: Challenges and strategies for successful adoption," Journal of biomedical informatics, vol. 44, no. 6, pp. 958-967, 2011.

[16]. Silow-Carroll S., Edwards J.N., and Rodin D., "Using electronic health records to improve quality and efficiency: the experiences of leading hospitals," Issue Brief (Commonw Fund), vol. 17, pp. 1-40, 2012.

[17]. Aguirre D., and Brown A., "Making Change Happen, and Making It Stick Delivering Sustainable Organizational Change." Booz \& Company, 2010. Noor Azizah Mohamadali et al. / Procedia Computer Science 124 (2017) 354-361 3618 Noor Azizah Mohamadali and Nurul Aqilah Zahari / Procedia Computer Science 00 (2018) 000-000

[18]. Ghazvini A., and Shukur Z., "Security challenges and success factors of electronic healthcare system," Procedia Technology, vol. 11, pp. 212-219, 2013.

[19]. Zaidan B., Zaidan A., and Mat Kiah M., "Impact of data privacy and confidentiality on developing telemedicine applications: A review participates opinion and expert concerns," International Journal Pharmacology, vol. 7, no. 3, pp. 382-387, 2011.

[20]. Shahri A. B., Ismail Z., and Rahim N., "Security effectiveness in health information system: through improving the human factors by education and training," Australian Journal of Basic and Applied Sciences, vol. 6, no. 12, pp. 226-233, 2012.

[21]. Blumenthal D., "Implementation of the federal health information technology initiative," New England Journal of Medicine, vol. 365, no. 25, pp. 2426-2431, 2011.

[22]. M. o. H. Malaysia, "HIMS Blueprint," Health Informatics Centre Planning Division Ministry of Health Malaysia, 2013.

[23]. Tsai F. S., "Security Issues in E-Healthcare," Journal of Medical and Biological Engineering, vol. 30, no. 4, pp. 209-214, 2010.

[24]. M. o. H. Malaysia, "Malaysia's Health," 2008.

[25]. Hassan R., "Implementation of total hospital information system (THIS) in Malaysian public hospitals: challenges and future prospects," International Journal of Business and Social Research, vol. 2, no. 2, pp. 33-41, 2012.

[26]. Schyve P. M., Leadership in Healthcare Organizations: A Guide to Joint Commission Leadership Standards, a Governance Institute White Paper: Governance Institute, 2009.

[27]. Cresswell K.M., Bates D. W., and Sheikh A., "Ten key considerations for the successful implementation and adoption of large-scale health information technology," Journal of the American Medical Informatics Association, vol. 20, no. e1, pp. e9-e13, 2013.
[28]. Yucel G., Cebi S., Hoege B., and Ozok A. F., “A fuzzy risk assessment model for hospital information system implementation," Expert Systems with Applications, vol. 39, no. 1, pp. 1211-1218, 2012.

[29]. Karim N. A., and Ahmad M., "An overview of electronic health record (EHR) implementation framework and impact on health care organizations in malaysia: A case study in Management of Innovation and Technology (ICMIT), 2010, IEEE Interenational Conference (pp. 84-89).

[30]. Mohamadali N.A.K, and Garibaldi J.M, "Understanding and Addressing the 'Fit'between User, Technology and Organization in Evaluating user Acceptance of Healthcare Technology." Proceedings of the International Conference on Helath Informatics - Volume 1: HealthInf (BIOSTEC 2012), ISBN: 978989-8425-88-1, pg. 119-124. DOI: $10.5220 / 0003696901190124$.

[31]. Mohamadali N.A.K., and Garibaldi J.M., "A Novel Evaluation Model of user Acceptance of Software Technology in Healthcare Sector." Proceedings of the Third International Conference on Helath Informatics - Volume 1: HealthInf (BIOSTEC 2010), ISBN 978-989-674- 016-0, pg 392-397. DOI: $10.5220 / 0002695703920397$.

[32]. Aziz N.F. Ab, and Mohamadali N.A., "The challenges of human factors for implementation of information systems in the healthcare," ARPN Journal of Engineering and Applied Sciences, vol. 10, no. 23, pp. 17914-17922, 2015

[33]. Noor Azizah Mohamadali et al. / Procedia Computer Science 124 (2017) 